\title{
Realization of mine personnel positioning WebGIS Based on SVG
}

$$
\text { Jitong Zhang }{ }^{1, a} \text { and Mengqing Feng, }{ }^{2, b}
$$

\author{
${ }^{1}$ School of Information Engineering, Zhengzhou University of Industrial Technology, Zhengzhou \\ Henan 451150, PR China
}

\begin{abstract}
${ }^{2}$ Machine learning and Data researching Institute, Zhengzhou University of Industrial Technology, Zhengzhou Henan 451150, PR China
\end{abstract}

a57478337@qq.com, b903901419@qq.com

Keywords: Personnel Positioning; SVG; AJAX; Vector Graphics

\begin{abstract}
Based on the self-development or third-party tool software, the CAD map is converted into SVG map file. SVG technology and AJAX technology are used to realize the underground personnel positioning vector graphics based on $\mathrm{B} / \mathrm{S}$ architecture, The underground personnel positioning vector graphics display, zoom, move, add device management and other functions.
\end{abstract}

\section{Introduction}

As one of the six systems of coal mine personnel positioning system in the mine production management, disaster relief, security decision-making and other aspects played a pivotal role[1][2]. How to integrate the real-time location information of mine activity object with mine geographic information and rely on graphic image processing technology, especially vector graphics system technology, to improve the visualization degree and real-time tracking performance of personnel and equipment location monitoring are important in coal mine personnel positioning system Features[3]. However, many of the current domestic positioning system does not really achieve the vector map management functions[4], mostly using bitmaps or other graphics formats, this graphics format is easy to operate, easy to implement, but the zoom prone to distortion, does not meet the requirements of personnel positioning system The How to develop and realize the real vector graphics management function has important practical significance.

\section{Related Technology}

SVG Technology. SVG scalable vector graphics are based on Extensible Markup Language (XML),A graphic format used to describe two-dimensional vector graphics. SVG strictly follows the XML syntax and describes the image content in descriptive language in text format, so it is a vector graphics format that is independent of image resolution [5].

AJAX Technology. AJAX refers to asynchronous JavaScript and XML, AJAX is the core of the JavaScript object XmlHttpRequest, XmlHttpRequest with JavaScript to the server to request and handle the response, without blocking the user. AJAX is not a new programming language, but a technology for creating better and faster and more interactive Web applications[6].

\section{System Main Function}

The underground personnel positioning vector graphics combines the current position of the underground personnel and the equipment with the GIS information of the underground roadway, and the visual display is displayed on the vector map, and the personnel and equipment can be effectively managed. underground Personnel Location Vector Management has the following features:

1 Can be achieved vector graphics editing, with unlimited zoom, zoom, mobile function.

2 Display the underground staff area in real time on the graph, click Show area staff details.

3 Real-time display of underground equipment location and status, and statistics of normal, abnormal total number of equipment. 
4 On the underground personnel positioning base station on the vector to add, location changes. 5 Has a ruler ranging function.

\section{System Implementation}

According to the requirement of vector management function of underground personnel positioning system, this system adopts the JSP programming language based on B / S architecture, SVG and AJAX technology to realize the management system of underground personnel positioning vector.

SVG Map File Generation. In order to truly reflect the underground location information, reduce the development workload, Usually using CAD to draw underground mapping. CAD drawings can not be directly applied in the JSP, CAD drawings must be converted to SVG map, and then use the SVG file $<$ embed $>$ tags embedded in the HTML.

Vector Graphics Zoom, the Realization of the Function. The system uses Javascript scripts to viewBox properties in SVG files, To operate, to achieve the SVG vector zoom and pan function. ViewBox = "x y width height", by changing the value of $\mathrm{x}, \mathrm{y}$ to achieve the move, change the value of width and height to zoom. Through the mouse wheel to zoom, hold down the left mouse button to move to achieve.

The Vector Graphics Shows the Real-Time Underground Personnel Distribution and the Realization of the Equipment State. The JSP moves by accessing the current underground personnel table and the device table in the database, State to generate the current distribution and number of underground personnel, the number of equipment and equipment status. The key is to the database corresponding to the data and vector map on the location and graphics, buttons associated with here, mainly by the <img $>$ and <input $>$ ID and database device_id corresponding to the realization of graphics and buttons and equipment and the real correspond. And to the underground personnel distribution and equipment status real-time display in the vector, you need to update the above data in a timely manner, where the use of AJAX technology, it can effectively prevent the entire page refresh.

Add the Device Implementation on the Graph. This function is mainly through the Javascript script to control the JS event to achieve, through the mouse click to add the reader button, and then in the graphics to place the device on the location of the left mouse button to pop up a dialog box, the system automatically to the current coordinate value Write the corresponding text box, and then manually enter the appropriate reader (base station) and the corresponding location name can be submitted by submitting the data into the corresponding database table, the page refresh after the new device icon appears in the Graphics on the.

Realization of Ruler Ranging Function. The ruler range is determined by the ratio of the SVG plot to the actual geographic location, But also take into account the current scale of the graphics, according to the distance between the two points of the formula can be obtained between the coordinates of the distance between the two points, and then according to the actual ratio and the current scale of the graphics can be Find the distance between two points.

\section{Summary}

The underground personnel positioning can provide a wealth of data, graphic information, from the ground real-time monitoring of underground personnel, equipment, the current location, walking path, statistics underground number and distribution of posts. Thus, through the production safety monitoring center, you can follow, To grasp the various locations of underground safety of various factors, so as to take positive effective precautions. But the underground personnel positioning system is a new thing, there are still many deficiencies, such as positioning accuracy is not high, graphics display and well, The actual environment there is a certain gap. However, I believe that with the development of science and technology, Exhibition, positioning accuracy, three-dimensional degree and the actual situation exactly the same underground personnel positioning system will be developed, and with the development of science and technology and constantly perfect. 


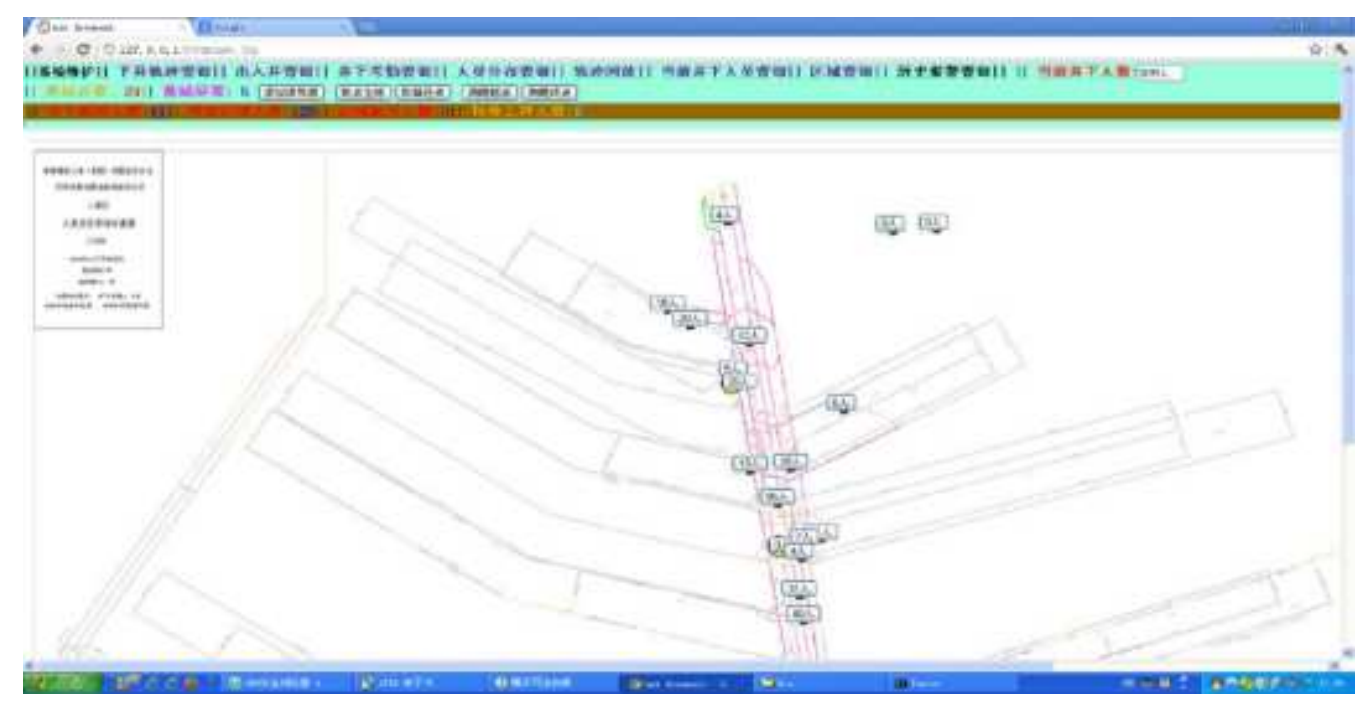

Figure 1. Finite Underground personnel positioning map before zooming

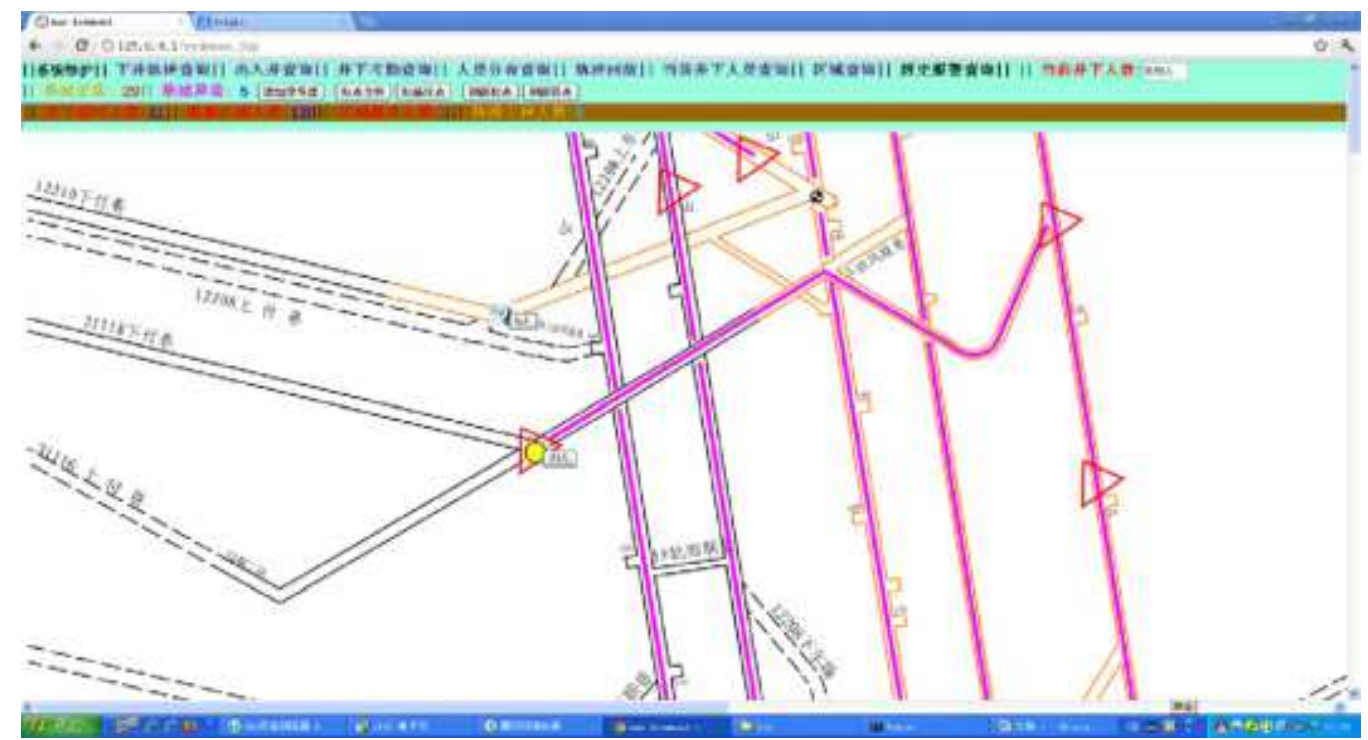

Figure 2. Finite Scaled underground personnel positioning map

\section{References}

[1] Bao Jianjun. DWG-based design of coal mine underground location monitoring vector graphics system design. Technology, Vol.10(2009),No.10,P.41.(In Chinese)

[2] Huang Kaiwei. SDG development practice . Electronic Industry Press, Vol.8 (2008), No.9, P.30-31. (In Chinese)

[3] Dave Crane Eric Pascarello. Li Kun translation. Ajax actual combat. People's Posts and Telecommunications Press, Vol.4(2006),No.4,P.51-52.(In Chinese)

[4] Jitong Zhang, Liang Xintao and Guo Zhen. Design of Underground Personnel Positioning System, China Western Technology,Vol.10(2011),No.10,P.33.(In Chinese)

[5] Zhou Wensheng. Research on WebGIS Based on SVG, Journal of Image and Graphics, Vol.5(2002),No.5,P.42.(In Chinese)

[6] Yanjie Feng. Realization Technology of WebGIS Based on SVG. Wuhan University.2005.(In Chinese)

[7] Zongsi Wang. Research on the Application of SVG Technology in Animation Production. Computer Age, Vol.6(2005,No.6,P.45-47.(In Chinese) 
[8] Web traffic reduction for infrequent update application using green Ajax. SANJAYA Ridwan. The 2nd IEEE International Conference on Information Management and Engineering (ICIME). 2010 